\title{
man \\ Microstructure, Hot Deformation Behavior, and Textural Evolution of Mg-3Sn-2Al-1Zn-0.6Nd Alloy
}

\author{
Yuhang Guo ${ }^{1, *}$, Yibo Dai ${ }^{1}$, Pan Chen ${ }^{1}$, Qianhao Zang ${ }^{1}$ and Zhenya Zhang ${ }^{2}$ \\ 1 School of Materials Science and Engineering, Jiangsu University of Science and Technology, \\ Zhenjiang 212003, China; $199060030 @$ stu.just.edu.cn (Y.D.); justchenpan@163.com (P.C.); \\ qhzang@just.edu.cn (Q.Z.) \\ 2 School of Material Science and Engineering, Jiangsu University, Zhenjiang 212013, China; zhangzy@ujs.edu.cn \\ * Correspondence: guoyuhang@just.edu.cn or guoyuhang@126.com
}

check for updates

Citation: Guo, Y.; Dai, Y.; Chen, P.; Zang, Q.; Zhang, Z. Microstructure, Hot Deformation Behavior, and Textural Evolution of Mg-3Sn-2Al-1Zn-0.6Nd Alloy. Metals 2022, 12, 364. https://doi.org/ $10.3390 /$ met12020364

Academic Editor: Sunghyuk Park

Received: 11 January 2022

Accepted: 15 February 2022

Published: 21 February 2022

Publisher's Note: MDPI stays neutral with regard to jurisdictional claims in published maps and institutional affiliations.

Copyright: (C) 2022 by the authors. Licensee MDPI, Basel, Switzerland. This article is an open access article distributed under the terms and conditions of the Creative Commons Attribution (CC BY) license (https:// creativecommons.org/licenses/by/ $4.0 /)$.

\begin{abstract}
To prepare wrought magnesium alloys with excellent plastic deformation properties, $\mathrm{Mg}$ $3 \mathrm{Sn}-2 \mathrm{Al}-1 \mathrm{Zn}-0.6 \mathrm{Nd}$ alloys were prepared. A hot compression test of $\mathrm{Mg}-3 \mathrm{Sn}-2 \mathrm{Al}-1 \mathrm{Zn}-0.6 \mathrm{Nd}$ alloy was carried out on a thermo-mechanical simulator. The hot deformation behavior of the alloys was studied, and the constitutive equations and the processing map at the strain of 0.8 were established. The processing map exhibited the stable domain (temperature range of $320-350{ }^{\circ} \mathrm{C}$ and strain rate range of $\left.0.001-0.04 \mathrm{~s}^{-1}\right)$ with the high power dissipation efficiency $(>30 \%)$. A large number of fine dynamic recrystallization (DRX) grains and deformed twinning existed in the alloy after the hot deformation. The dominant texture of the Mg-3Sn-2Al-1Zn-0.6Nd alloy is $<0001>/ / C D$ texture after the hot deformation. The continuous dynamic recrystallization (CDRX) and discontinuous dynamic recrystallization (DDRX) were the dominant recrystallization mechanisms, and $\{10 \overline{1} 2\}$ extension twinning also occurred in the alloy during the hot deformation.
\end{abstract}

Keywords: magnesium alloy; constitutive equations; processing map; dynamic recrystallization; textural evolution

\section{Introduction}

As typical wrought magnesium alloys, Al-Zn (AZ) series magnesium alloys have been widely applied in transportation industries because of their low density, high specific strength, good damping capacities, etc. [1,2]. It is widely accepted that the addition of Sn could improve the hot-working properties of magnesium alloys during hot compression, which is conducive to the promotion of dynamic recrystallization (DRX) of magnesium alloys, the reduction of flow stress, and the improvement of hot-working properties [3-5]. Jiang et al. [6] studied the influence of Sn element on the microstructure evolution of magnesium alloy during the hot compression behavior by adding $2 \mathrm{wt} . \%$ Sn element to AZ80 magnesium alloy. The results indicated that the addition of $\mathrm{Sn}$ reduced the critical stress and strain of DRX, thereby promoting DRX. Zou et al. [7] studied the effect of the addition of $\mathrm{Sn}$ with different contents on the dynamic recrystallization of $\mathrm{Mg}-5 \mathrm{Zn}-1 \mathrm{Mn}$ alloy under a high strain rate through hot compression experiments. It is found that solute Sn atoms can affect DRX by changing the stacking fault energy (SFE) and the content of precipitates. The DRX fraction first increases and then decreases with the addition of the $\mathrm{Sn}$ element. When the Sn element content is $0.9 \%$, the Mg- $\mathrm{Zn}-1 \mathrm{Mn}-0.9 \mathrm{Sn}$ alloy exhibits the greatest degree of DRX.

Elemental alloying is an effective method for improving the thermal processing performance of magnesium alloys, and rare-earth(RE)-element-containing magnesium alloys also show excellent mechanical properties and creep resistance [8]. $\mathrm{Nd}$ can improve creep resistance because of the combined effect of solid solution and precipitation hardening [9-12]. Wang et al. [13] found that the addition of the $\mathrm{Nd}$ element can refine the $\beta-\mathrm{Mg} 17 \mathrm{Al} 12$ phase and suppress the discontinuous precipitation of grain boundaries during the aging 
process. When the addition amount of $\mathrm{Nd}$ is $1 \%$, the grain size of as-cast AZ80 was reduced from $448 \mu \mathrm{m}$ to $125 \mu \mathrm{m}$ and the overall performance was the best. Xu et al. [9] studied the influence of $1.5 \mathrm{wt}$ \% $\mathrm{Nd}$ addition on microstructures of the as-extruded ZK60 alloy. The results demonstrated that the addition of $\mathrm{Nd}$ refined dynamically recrystallized grains but barely influenced the texture.

Processing maps can effectively predict material structures and deformation mechanisms and their relationships between hot working parameters and are used for the optimization of current processes and controlling the microstructure evolution [14-18]. The final microstructure and mechanical properties of the alloys are largely determined by hot deformation behavior [19-22]. Thus, it is necessary to investigate the microstructure evolution during hot deformation for new alloys. Wang et al. [23] studied the hot working behavior of ZK60 alloy by squeeze casting in the temperature range of $250-450{ }^{\circ} \mathrm{C}$ and the strain rate range of $0.001-10 \mathrm{~s}^{-1}$ by establishing processing maps. The result showed that in the temperature range of $300-375^{\circ} \mathrm{C}$ and the strain rate range of $0.001-0.01 \mathrm{~s}^{-1}$ were the best hot working parameters of ZK60 alloy, and the peak efficiency reached 36\% at $375{ }^{\circ} \mathrm{C}$ and $0.001 \mathrm{~s}^{-1}$. Cheng et al. [24] investigated the hot deformation behavior of the fine-grained $\mathrm{Mg}-8 \mathrm{Sn}-2 \mathrm{Zn}-2 \mathrm{Al}\left(\mathrm{TZA} 822, \mathrm{wt} \%\right.$ ) alloy at a temperature range of $150-350{ }^{\circ} \mathrm{C}$ and a strain rate of $0.01-10 \mathrm{~s}^{-1}$ by establishing a thermal processing map. It was found that the deformation temperature had a significant effect on the work hardening behavior of the alloy. The hot working diagram at $350{ }^{\circ} \mathrm{C}$ showed two stable regions of high power dissipation efficiency, which were $350{ }^{\circ} \mathrm{C} / 0.01 \mathrm{~s}^{-1}$ and $350{ }^{\circ} \mathrm{C} / 10 \mathrm{~s}^{-1}$.

In the previous research process, the team studied the thermal deformation behavior of Mg-3Sn-2Al-1Zn [25] and Mg-3Sn-2Al-1Zn-5Li [26] alloys at different deformation temperatures and strain rates. The results show that the Mg-3Sn-2Al-1Zn alloy has good thermal deformation properties, and the addition of Li can reduce the activation energy of the Mg-3Sn-2Al-1Zn alloy and promote the dynamic recovery of the alloy. Compared with cast magnesium alloys, wrought magnesium alloys have better mechanical properties. It is of great significance to research and develop high-performance wrought magnesium alloys and expand the application of wrought magnesium alloys in automotive light weighting. According to the literature [8-13], the Nd element has a significant effect on grain refinement. Therefore, to further improve the hot deformation performance of the $\mathrm{Mg}-3 \mathrm{Sn}-2 \mathrm{Al}-1 \mathrm{Zn}$ alloy, by adding the $\mathrm{Nd}$ element to the Mg-3Sn-2Al-1Zn alloy, the Mg3Sn-2Al-1Zn-0.6Nd alloy was studied at different deformation temperatures and thermal deformation behavior at strain rates. The constitutive equations will be established to investigate the relationship among the flow stress, strain, strain rate, and deformation temperature. The processing map of the studied alloy will be established to optimize hot deformation process parameters. Microstructure and texture evolution will also be discussed to clarify the deformation mechanisms of the studied alloy.

\section{Experimental Procedure}

Mg-3Sn-2Al-1Zn-0.6Nd alloy was made using commercially pure $\mathrm{Mg}(99.9 \mathrm{wt} \%), \mathrm{Sn}$ (99.93 wt\%), Zn (99.995 wt\%), Al (99.999 wt\%), and Mg-21Nd (wt\%) master alloy, which was melted in an electric furnace under a covering flux in a protective atmosphere $(0.5 \mathrm{vol} \%$ $\left.\mathrm{SF}_{6}+99.5 \mathrm{vol} \% \mathrm{CO}_{2}\right)$. After the alloy was completely melted, it was kept at $720{ }^{\circ} \mathrm{C}$ for $20 \mathrm{~min}$, followed by mechanical stirring for $2 \mathrm{~min}$ to ensure a homogeneous composition. After the smelting was completed, the liquid alloy was poured into a steel mold that had been preheated to $150^{\circ} \mathrm{C}$, and the alloy was taken out from the steel mold after the alloy was cooled. Subsequently, the alloy was homogenized at $400{ }^{\circ} \mathrm{C}$ for $24 \mathrm{~h}$, and after the heat treatment, the alloy was cut into $\varnothing 10 \times 15 \mathrm{~mm}$ cylindrical compression specimens. Hot deformation tests were performed on a Gleeble-3500 thermo-mechanical simulator, where the deformation temperature and the strain rate were $200,250,300,350{ }^{\circ} \mathrm{C}$ and 0.001 , $0.01,0.1,1 \mathrm{~s}^{-1}$, respectively, obtained one qualified curve from one qualified sample in the same conditions. Before the thermocompression experiment, the sample was heated to the target temperature at a heating rate of $5{ }^{\circ} \mathrm{C} / \mathrm{s}$ and kept at the target temperature 
for $5 \mathrm{~min}$. The compressed sample was compressed to a true strain of 0.8 and water quenched immediately after compression to preserve the microstructure of the sample. The deformed specimens were sectioned parallel to the compression axis along the direction of the centerline, and deformed microstructure was observed on the center of the section by optical microscope (OM; ZEISS Axiolmager A2m) and electron backscatter diffraction (EBSD). The phase structure and Macro texture are identified by Parnike $X^{\prime}$ Pert PRO MPD (Holland Panalytical, Almelo, The Netherlands) X-ray diffraction (XRD) diffractometer with $\mathrm{Cu}$ radiation. The $\mathrm{OM}$ observations were carried out after etching in a solution containing $100 \mathrm{~mL}$ ethanol, $3 \mathrm{~g}$ picric acid, $20 \mathrm{~mL}$ acetic acid, and $25 \mathrm{~mL}$ water, the time of etching was $30 \mathrm{~s}$. The EBSD analysis was conducted using an Oxford Instruments-Nordlys Nano EBSD detector on the SEM operating at $20 \mathrm{kV}$. The samples prepared for EBSD analysis were additionally performed by ion etching in a Leica RES101 ion etching apparatus (Bal-Tec Inc, Wetzlar, Germany) after mechanically polishing. The EBSD data was conducted using HKL Channel 5.

\section{Results and Discussion}

\subsection{Microstructural Characterization and Analyze}

The original microstructure of Mg-3Sn-2Al-1Zn-0.6Nd alloy after homogenization is shown in Figure 1. The XRD pattern in Figure 1a shows that after homogenization, the alloy is mainly composed of $\alpha-\mathrm{Mg}$ phase and some weak peaks representing the $\mathrm{Mg}_{2} \mathrm{Sn}$ phase can be observed. According to Figure 1b, it can be seen that some incompletely dissolved phases are uniformly distributed in the matrix, and in addition to $\mathrm{Mg}$ and $\mathrm{Sn}$ elements, a high proportion of $\mathrm{Nd}$ elements are also present in the undissolved phases. From Figure 1c,d, it can be seen that the original microstructure of this alloy also shows a random orientation after homogenization treatment, and the grain size is widely distributed between $5 \mu \mathrm{m}$ and $650 \mu \mathrm{m}$, with a larger average grain size of $90.53 \mu \mathrm{m}$.

(a)

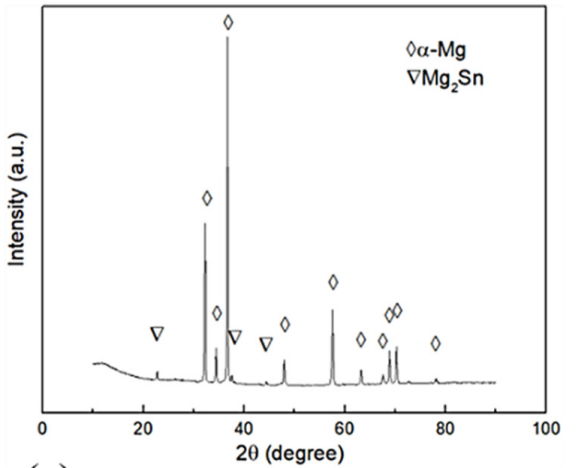

(c)

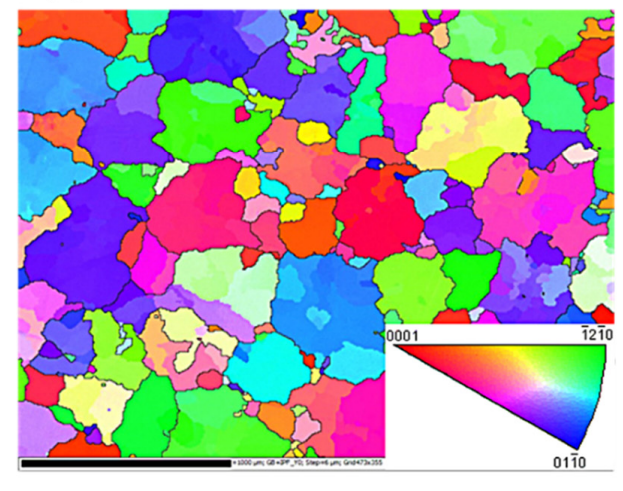

(b)

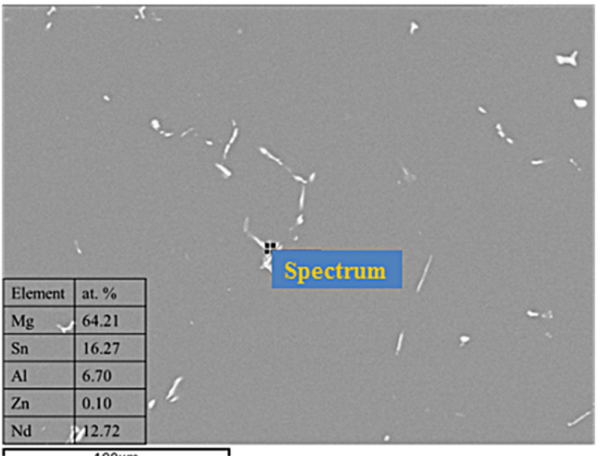

(d)

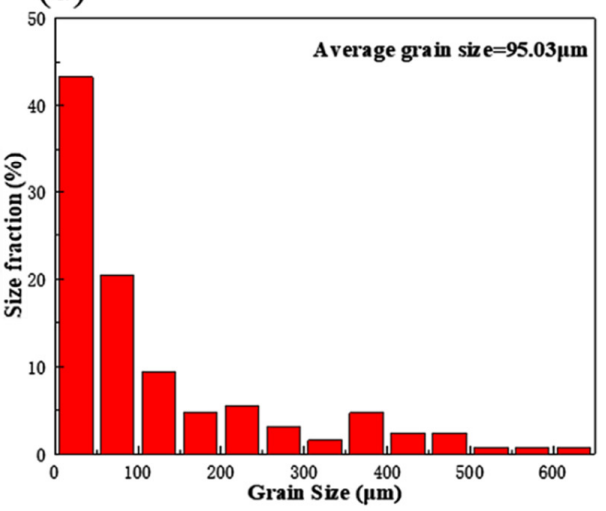

Figure 1. Microstructure of the as-homogenized Mg-3Sn-2Al-1Zn-0.6Nd alloy (a) XRD imagine; (b) EDS map; (c) IPF map; (d) grain distribution statistics map. 


\subsection{Hot Compression Flow Behavior}

The true stress-true strain curves of Mg-3Sn-2Al-1Zn-0.6Nd alloy at different strain rates are shown in Figure 2. The flow stress increased to the peak stress quickly with a small strain. The flow stress increased sharply due to work hardening during this stage [27-29]. The obvious softening stage was presented subsequently, the softening caused by dynamic recovery and recrystallization was the predominant way at this stage. When the flow stress decreased to a certain degree, the balance of softening effect and work hardening effect was obtained, and the flow stress tended to be stale at this stage. Under the same temperature, all the flow stresses increase with increasing strain rate. This is attributed to the short time for dynamic recovery and recrystallization with a larger strain rate. When the strain rate is constant, an increase in the deformation temperature leads to the reduction of flow stress. In Figure $2 c$, the curve at $350{ }^{\circ} \mathrm{C}$ shows typical DRX characteristics from the overall trend. However, during strain hardening, the stress value shows an unusual decline. Wang et al. [30] and Chen et al. [31] also reported the unusual decline of the true stress-true strain curves. Chen et al. [31] attributed the sudden change of stress to the change of slip mechanism through microstructure observation.
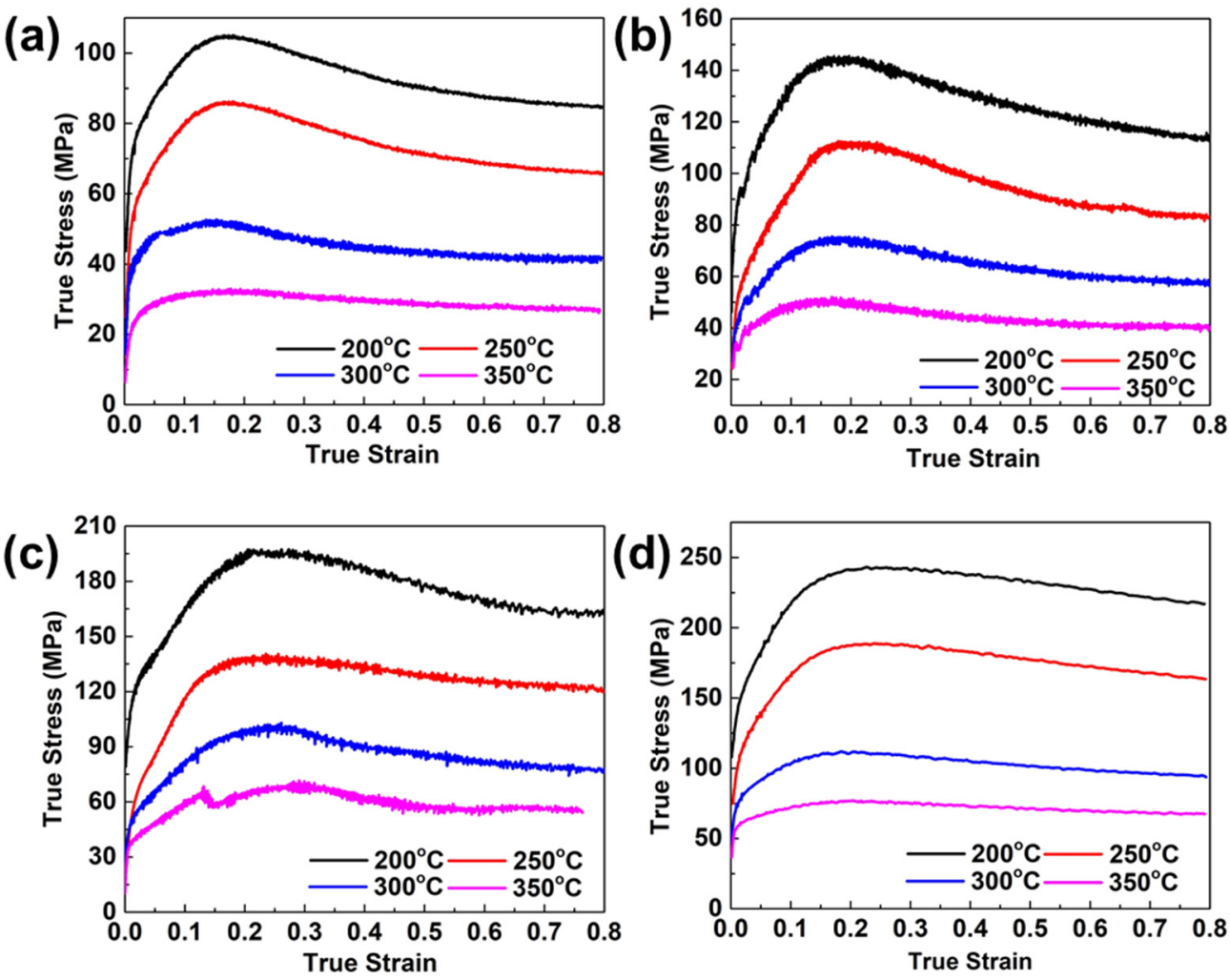

Figure 2. True stress-strain curves at different deformation temperatures and different strain rates: (a) $0.001 \mathrm{~s}^{-1}$; (b) $0.01 \mathrm{~s}^{-1}$; (c) $0.1 \mathrm{~s}^{-1}$ and (d) $1 \mathrm{~s}^{-1}$.

\subsection{Deformation Constitutive Equation}

The Arrhenius-type model is widely applied to estimate the correlation among flow stress, strain rate, and deformation temperature, which predict the hot deformation behavior of materials. The constitutive equation is given as follows $[32,33]$ :

$$
\begin{gathered}
Z=\dot{\varepsilon} \exp (Q / R T) \\
\dot{\varepsilon}=A f(\sigma) \exp (-Q / R T)
\end{gathered}
$$

where $\dot{\varepsilon}$ is the strain rate, $\sigma$ is the flow stress for a given strain, $Q$ is the activation energy for deformation, $R$ is the universal gas constant, $T$ is the absolute temperature, $A$ is the 
constant, and $f(\sigma)$ is the stress function. Equation (2) can be described under a wide range of stress as follows:

$$
\begin{gathered}
\dot{\varepsilon}=A_{1} \sigma^{n_{1}} \exp (-Q / R T) \alpha \sigma<0.8 \\
\dot{\varepsilon}=A_{2} \exp (\beta \sigma) \exp (-Q / R T) \alpha \sigma>1.2 \\
\dot{\varepsilon}=A[\sinh (\alpha \sigma)]^{n} \exp (-Q / R T) \text { for all } \sigma
\end{gathered}
$$

where $A, A_{1}, A_{2}, n_{1}, n$, and $\beta$ are constants, and the stress multiplier $\alpha$ can be defined as $\alpha=\beta / n_{1}$. Taking the natural logarithm of both sides of Equations (3) and (4) and derivation, it can be expressed as follows:

$$
\begin{gathered}
n_{1}=\frac{\partial \ln \dot{\varepsilon}}{\partial \ln \sigma} \\
\beta=\frac{\partial \ln \dot{\varepsilon}}{\partial \sigma}
\end{gathered}
$$

Take $\sigma_{P}$ as the peak stress of different deformation conditions and make a linear graph of $\ln \sigma_{P}-\ln (\dot{\varepsilon})$ and $\sigma_{P}-\ln (\dot{\varepsilon})$, as shown in Figure 3a,b, respectively. From Equations (6) and (7), the average slopes for plots of $\ln \sigma_{P}-\ln (\dot{\varepsilon})$ and $\sigma_{P}-\ln (\dot{\varepsilon})$ are the values of $n_{1}$ and $\beta$, respectively. The values of $n_{1}$ and $\beta$ for the alloy were 8.39346 and $0.09022 \mathrm{MPa}^{-1}$, respectively. As $\alpha=\beta / n_{1}$, the value of $\alpha$ can be obtained as $0.01075 \mathrm{MPa}^{-1}$.
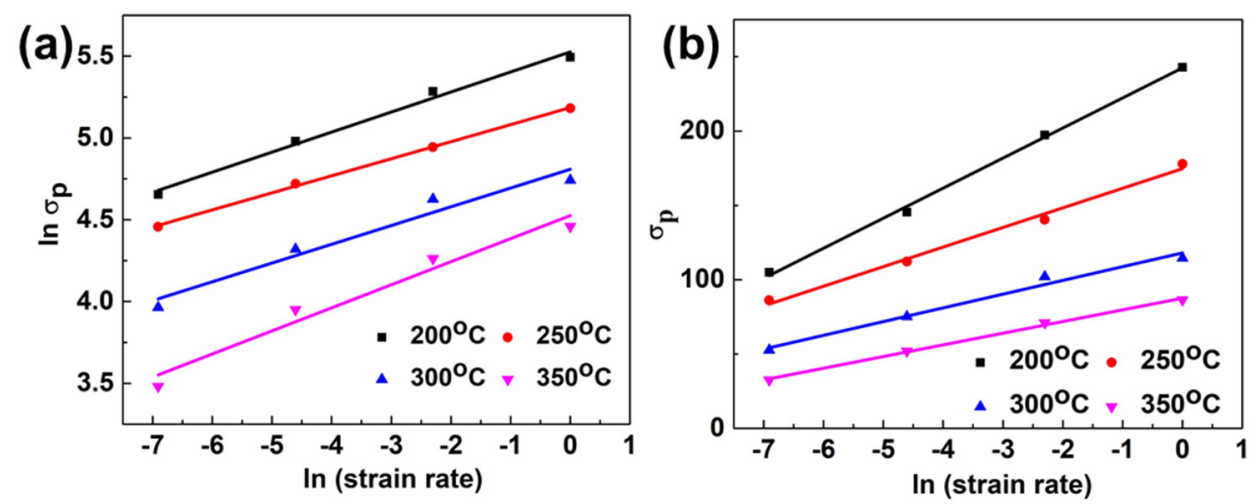

Figure 3. The relationship between peak stress and strain rate: (a) $\ln \sigma_{P}-\ln (\dot{\varepsilon})$ and (b) $\sigma_{P}-\ln (\dot{\varepsilon})$.

Taking the natural logarithm of both sides of Equation (5), the following relation is obtained:

$$
\ln \dot{\varepsilon}=n \ln [\sin (\alpha \sigma)]+\ln A-\frac{Q}{R T}
$$

The constant $n$ and deformation activation energy $Q$ can be determined from Equation (8):

$$
\begin{gathered}
n=\frac{\partial \ln \dot{\varepsilon}}{\partial \ln [\sinh (\alpha \sigma)]} \\
Q=R \frac{\partial \ln \dot{\varepsilon}}{\partial \ln [\sinh (\alpha \sigma)]} \frac{\partial \ln [\sinh (\alpha \sigma)]}{\partial(1 / T)}=R n S
\end{gathered}
$$

From Equation (9), the $n$ was calculated from the average slope for plots of $\ln (\dot{\varepsilon})-$ $\ln \left[\sinh \left(\alpha \sigma_{P}\right)\right]$, as shown in Figure 4 a. Figure $4 \mathrm{~b}$ shows the plot of $\ln \left[\sinh \left(\alpha \sigma_{P}\right)\right]-1000 / T$, the $S$ can be calculated from the average slope for plots, and then the $Q$ was obtained. The values of $n$ and $S$ for the alloy were 5.83763 and 3.05152, respectively, so the deformation activation energy $Q$ for the alloy was $148.103 \mathrm{~kJ} / \mathrm{mol}$. Compared with the literature [25], it was found that the addition of the $\mathrm{Nd}$ element can effectively reduce the deformation activation energy $Q$. 

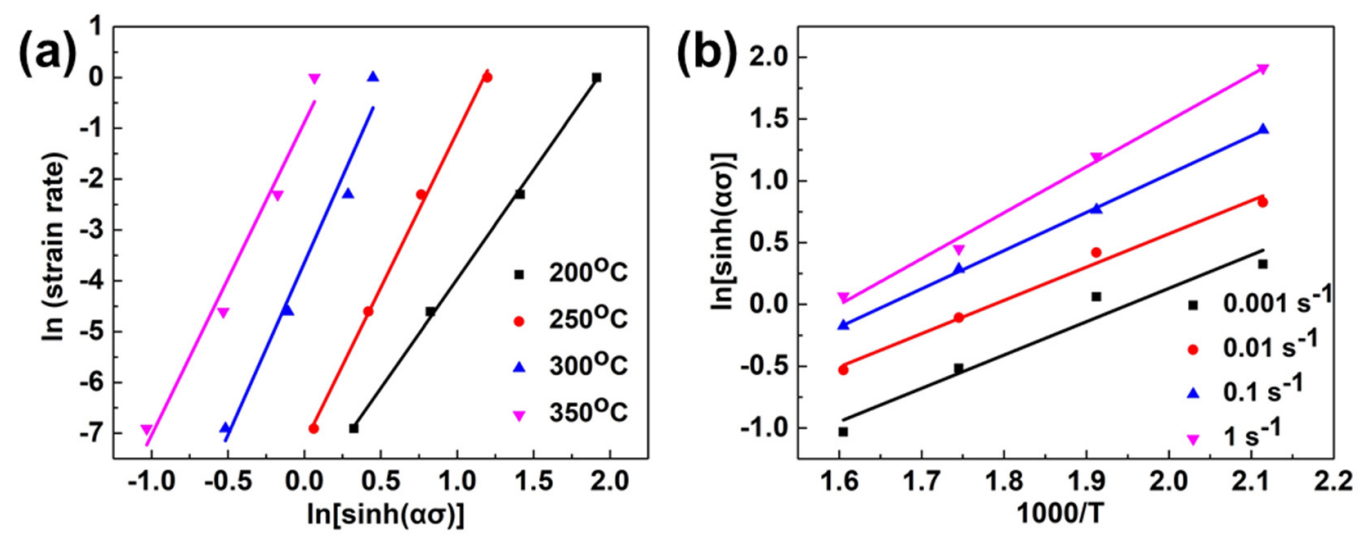

Figure 4. Relationship between peak stress and strain rate, deformation temperature: $(\mathbf{a}) \ln (\dot{\varepsilon})-$ $\ln \left[\sinh \left(\alpha \sigma_{P}\right)\right]$ and $(\mathbf{b}) \ln \left[\sinh \left(\alpha \sigma_{P}\right)\right]-1000 / \mathrm{T}$.

The values of $Z$ at the different deformation temperatures and strain rate can be calculated after the deformation activation energy $Q$ obtained by Equation (1). From Equations (1) and (5), the following relation is obtained:

$$
\ln Z=\ln A+n \ln [\sinh (\alpha \sigma)]
$$

Figure 5 shows the relationship between the Zener-Hollomon parameter $(\ln Z)$ and $\ln \left[\sinh \left(\alpha \sigma_{P}\right)\right]$ for the alloy. A best linear relationship between $\ln Z-\ln \left[\sinh \left(\alpha \sigma_{P}\right)\right]$ was presented. The intercept and slope for the plot are the values of $\ln A$ and $n$, respectively. Thus, the value of $\ln A$ and $n$ for the alloy were 27.49424 and 5.67531, respectively. The value of $n$ as 5.67531 was within the range obtained in Figure 4a. Therefore, the Arrhenius-type model can be used to predict the hot deformation behavior in this work.

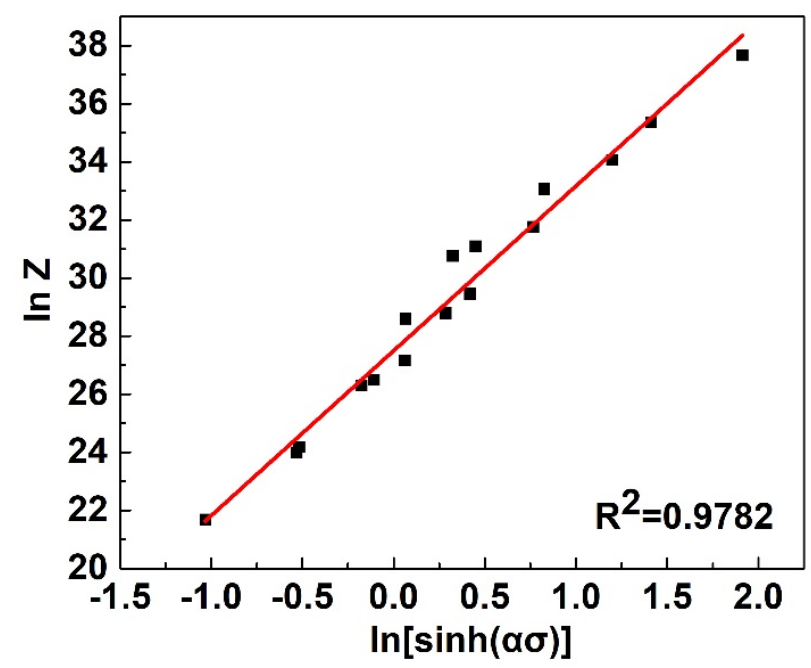

Figure 5. The relationship between $\ln Z$ and $\ln \sinh \left(\alpha \sigma_{P}\right)$.

By substituting the value of $\alpha, A, n$, and $Q$ into Equation (5), the deformation constitutive equation of $\mathrm{Mg}-3 \mathrm{Sn}-2 \mathrm{Al}-1 \mathrm{Zn}-0.6 \mathrm{Nd}$ alloy suitable for all stress states can be expressed as follows:

$$
\dot{\varepsilon}=8.72165 \times 10^{11}[\sinh (0.01075 \sigma)]^{5.83763} \exp \left(-\frac{148102.52}{R T}\right)
$$




\subsection{Processing Maps}

The processing map could be obtained based on the principles of the dynamic materials model (DMM) [34,35]. The workpiece (power input, $P$ ) is considered to be a dissipater, which is the sum of $G$ content (the viscoplastic heat caused by plastic deformation) and $J$ co-content (the internal energy change of the material through microstructural changes). The strain rate sensitivity $m$ can be given by:

$$
\mathrm{m}=\frac{d J}{d G}=\frac{\dot{\varepsilon} d \sigma}{\sigma d \dot{\varepsilon}}=\frac{d(\ln \sigma)}{d(\ln \dot{\varepsilon})}
$$

$J$ co-content can be expressed as:

$$
J=P-G=\sigma \dot{\varepsilon}-\int_{0}^{\dot{\varepsilon}} \sigma d \dot{\varepsilon}=\sigma \dot{\varepsilon}-\int_{0}^{\dot{\varepsilon}} K \dot{\varepsilon}^{m} d \dot{\varepsilon}=\frac{m}{m+1} \sigma \dot{\varepsilon}
$$

The efficiency of power dissipation $(\eta)$ can be given by:

$$
\eta=\frac{J}{J_{\max }}=\frac{2 m}{m+1}
$$

From the variation of power dissipation $(\eta)$ with deformation temperatures and strain rates, the power dissipation maps could be established. The flow instability should also be considered to optimize hot deformation parameters. The condition for flow instability can be expressed as:

$$
\xi(\dot{\varepsilon})=\frac{\partial \ln \left(\frac{m}{m+1}\right)}{\partial \ln \dot{\varepsilon}}+m \leq 0
$$

The instability map could be obtained from the variation of instability parameter $\xi(\dot{\varepsilon})$ with deformation temperatures and strain rates. The processing map could be established by superimposing the instability map over the power dissipation map.

Figure 6 shows the hot processing map at the strain of 0.8. The instability regions $(\xi(\dot{\varepsilon})<0)$ were represented as the grey areas in the processing maps. The $\eta$ values as percent were given by the values on contours. When designing the hot processing procedure, deformation parameters in the instability domain should be avoided as far as possible. In general, the domains instability regions with high power dissipation efficiency $(\eta>30 \%)$ are considered as optimum hot deformation processing parameters [36,37]. The safety domain mainly occurred at higher temperatures while the instability domain mainly occurred at higher strain rates, which are consistent with the previous research [38-40]. The Mg-3Sn-2Al-1Zn-0.6Nd magnesium alloy has the stability domain (the temperature range of $320-350{ }^{\circ} \mathrm{C}$ and the strain rate range of $0.001-0.04 \mathrm{~s}^{-1}$ ) with high power dissipation efficiency during hot deformation. From the point of view of strain rate, the addition of the $\mathrm{Nd}$ element reduced the strain rate range of the instability zone at low temperature from 0.01-1 s ${ }^{-1}$ to $0.1-1 \mathrm{~s}^{-1}$ [25]. On the other hand, the addition of the $\mathrm{Nd}$ element effectively reduced the deformation activation energy of the magnesium alloy, promoted dynamic recrystallization, and improved the power dissipation coefficient in the safe area.

\subsection{Microstructural Evolution}

Figure 7 shows the OM of the Mg-3Sn-2Al-1Zn-0.6Nd alloys under different hot deformation conditions. Due to the low temperature and the high strain rate, the characteristic of plastic instability was observed in the alloy under the condition of $200{ }^{\circ} \mathrm{C} / 1 \mathrm{~s}^{-1}$, see Figure 7a. Based on the processing map of Mg-3Sn-2Al-1Zn-0.6Nd alloy, the deformation parameter of $200{ }^{\circ} \mathrm{C} / 1 \mathrm{~s}^{-1}$ for the alloy was within the instability regions. With the increase of temperature and the decrease of strain rate, a large number of fine DRX grained and deformed twins existed in the alloy under the condition of $250{ }^{\circ} \mathrm{C} / 0.01 \mathrm{~s}^{-1}$, and the coarse deformed grains were still observed, see Figure $7 \mathrm{~b}$. With the increase of deformation temperature to $350{ }^{\circ} \mathrm{C}$, the DRX grains were observed in the alloy under the condition of 
$350{ }^{\circ} \mathrm{C} / 0.1 \mathrm{~s}^{-1}$ and $350{ }^{\circ} \mathrm{C} / 0.001 \mathrm{~s}^{-1}$. At the same time, the twin grains were also found in the alloys. The microstructure evolution within the different regions was investigated based on the processing maps, which show good agreement between the processing maps and the microstructure evolution. Figure 8 shows the EBSD IPF maps of Mg-3Sn-2Al-1Zn-0.6Nd alloy under different hot deformation conditions. The IPF maps show similar structures to the OM. The fine DRX grains and the coarse deformed grains coexist in the alloys, and fine DRX grains formed around the coarse deformed grains. The size of DRX grains increased with the increase of deformation temperature or the decrease of strain rate. At the same time, the gradient in the orientation of the deformed grain was observed under different conditions, which was attributed to substructure formation and CDRX [15].

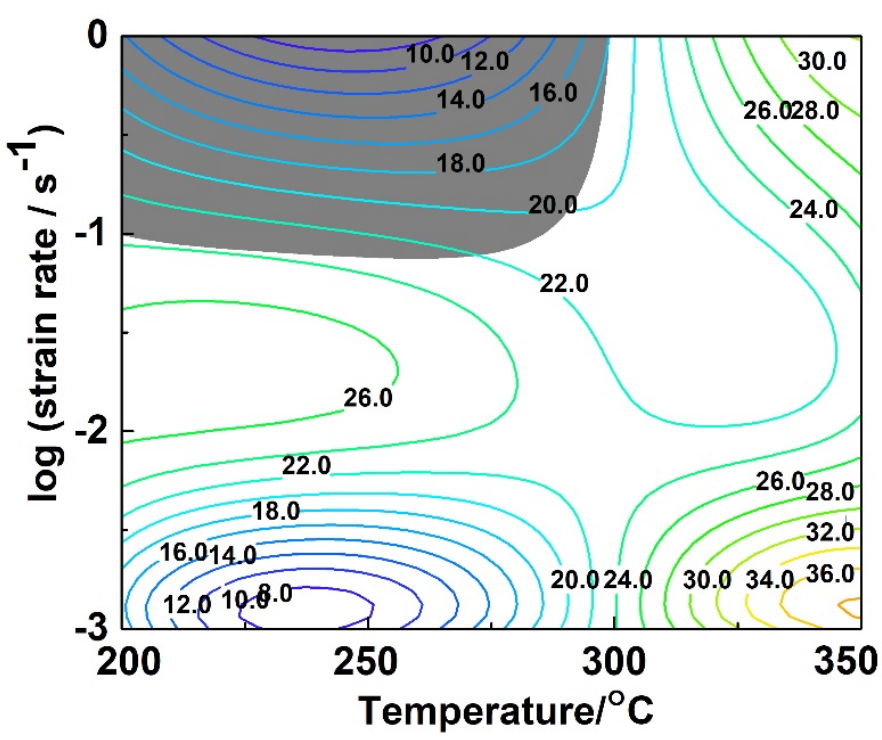

Figure 6. Processing map of Mg-3Sn-2Al-1Zn-0.6Nd alloy at the strain of 0.8 .
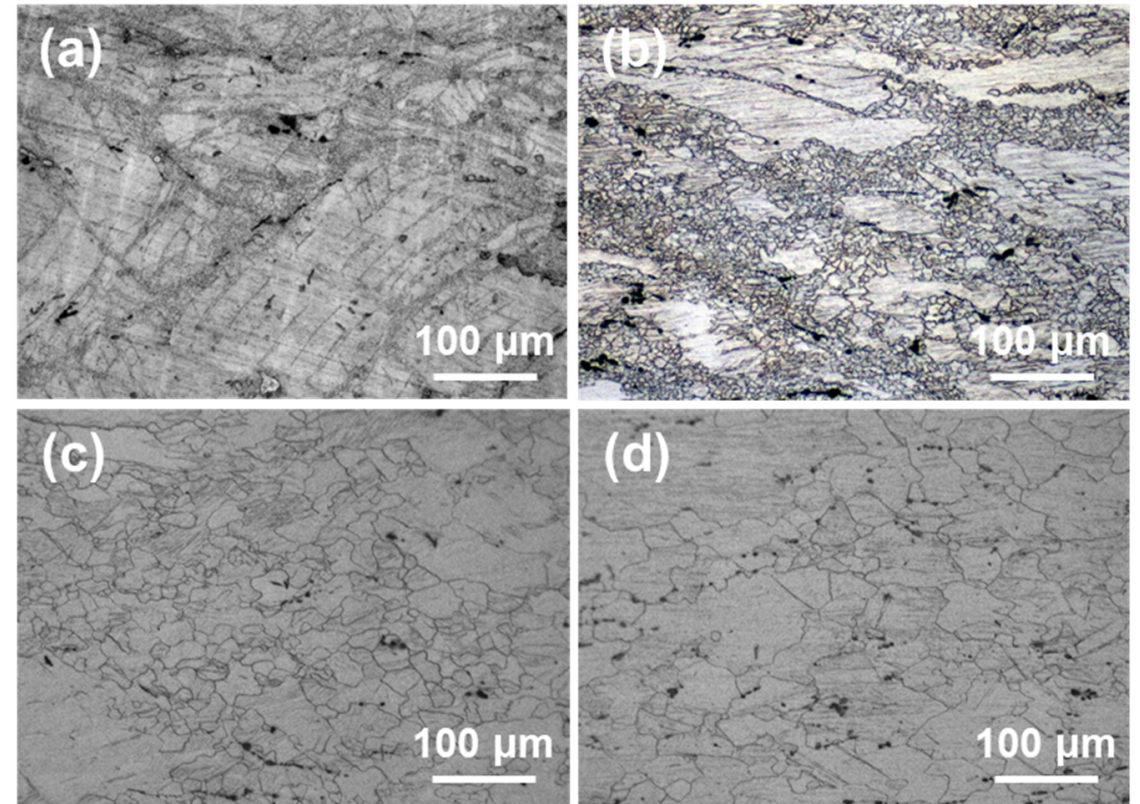

Figure 7. $\mathrm{OM}$ of $\mathrm{Mg}-3 \mathrm{Sn}-2 \mathrm{Al}-1 \mathrm{Zn}-0.6 \mathrm{Nd}$ alloy under different hot deformation conditions: (a) $200{ }^{\circ} \mathrm{C} / 1 \mathrm{~s}^{-1}$, (b) $250{ }^{\circ} \mathrm{C} / 0.01 \mathrm{~s}^{-1}$, (c) $350{ }^{\circ} \mathrm{C} / 0.1 \mathrm{~s}^{-1}$, and (d) $350{ }^{\circ} \mathrm{C} / 0.001 \mathrm{~s}^{-1}$. 

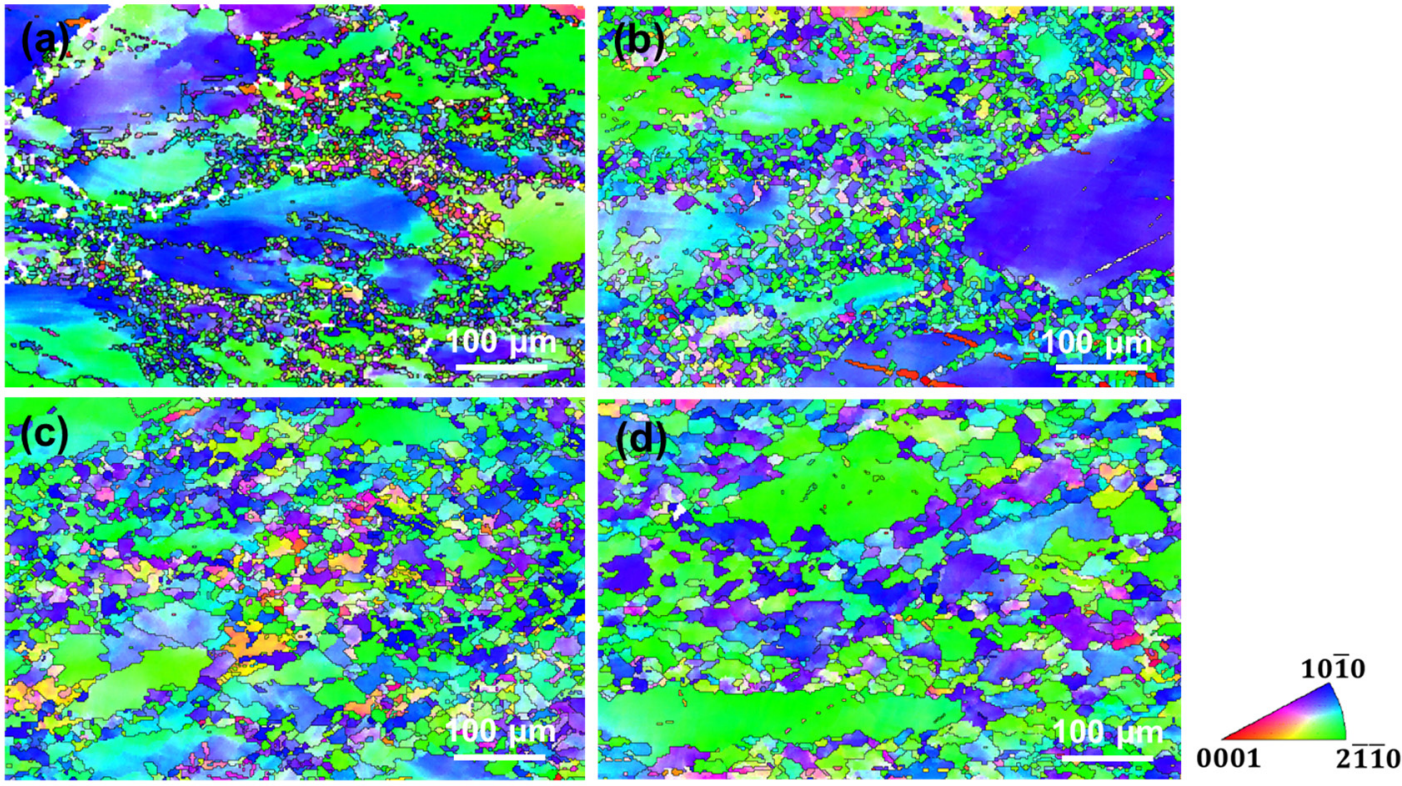

Figure 8. EBSD IPF maps of Mg-3Sn-2Al-1Zn-0.6Nd alloy under different hot deformation conditions: (a) $250{ }^{\circ} \mathrm{C} / 0.01 \mathrm{~s}^{-1}$, (b) $300{ }^{\circ} \mathrm{C} / 0.01 \mathrm{~s}^{-1}$, (c) $350{ }^{\circ} \mathrm{C} / 0.01 \mathrm{~s}^{-1}$, and (d) $350{ }^{\circ} \mathrm{C} / 0.001 \mathrm{~s}^{-1}$.

To investigate texture evolution under the different deformation conditions, the pole figures by EBSD of the Mg-3Sn-2Al-1Zn-0.6Nd alloys and macro texture by XRD under different hot deformation conditions are shown in Figures 9 and 10. As can be seen from Figure 9, similar textures were obtained in the Mg-3Sn-2Al-1Zn-0.6Nd alloy under different hot deformation conditions. The pole density points were distributed at both ends of the $\mathrm{CD}$ on $\{0001\}$ pole figure, and the pole density points were distributed along with the TD on $\{11 \overline{2} 0\}$ pole figure and $\{10 \overline{1} 0\}$ pole figure. It suggests that $<0001>/ / C D$ texture is the dominant texture for the $\mathrm{Mg}-3 \mathrm{Sn}-2 \mathrm{Al}-1 \mathrm{Zn}-0.6 \mathrm{Nd}$ alloy after hot deformation. In contrast to Figures 9 and 10, this trend remains largely consistent with the macro texture.

(a)

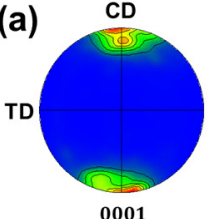

0001

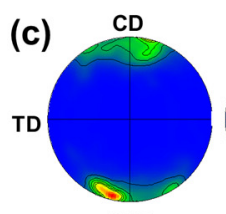

0001
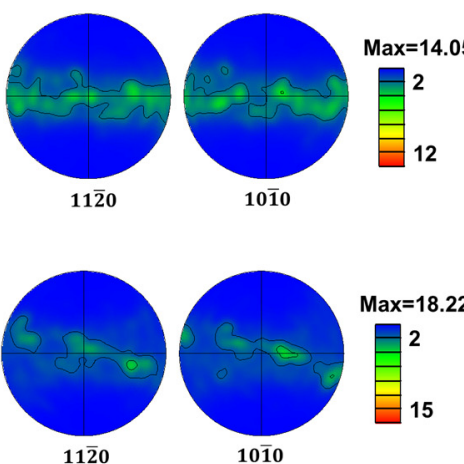

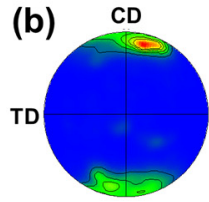

0001

(d)

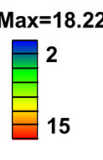

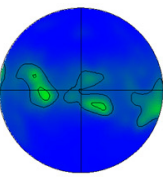
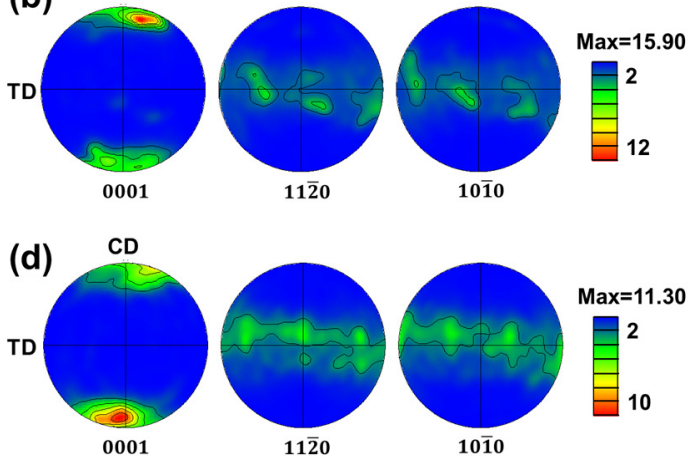

Figure 9. Pole figures of $\mathrm{Mg}-3 \mathrm{Sn}-2 \mathrm{Al}-1 \mathrm{Zn}-0.6 \mathrm{Nd}$ alloy under different hot deformation conditions: (a) $250{ }^{\circ} \mathrm{C} / 0.01 \mathrm{~s}^{-1}$, (b) $300{ }^{\circ} \mathrm{C} / 0.01 \mathrm{~s}^{-1}$, (c) $350{ }^{\circ} \mathrm{C} / 0.01 \mathrm{~s}^{-1}$, and (d) $350{ }^{\circ} \mathrm{C} / 0.001 \mathrm{~s}^{-1}$. 
(a)

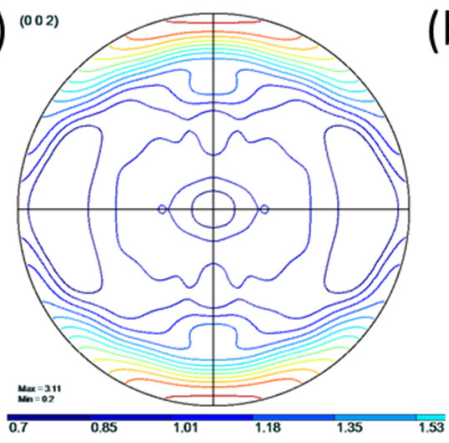

(c)

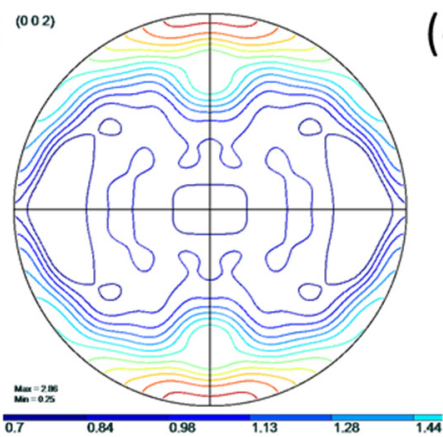

(b)

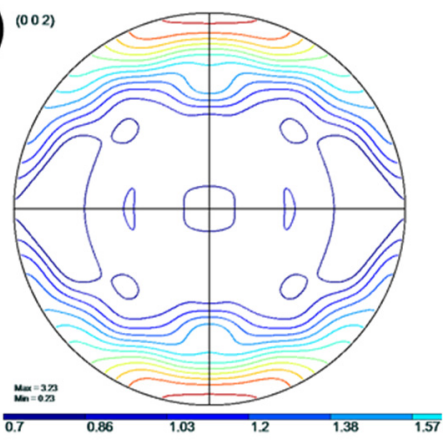

(d)

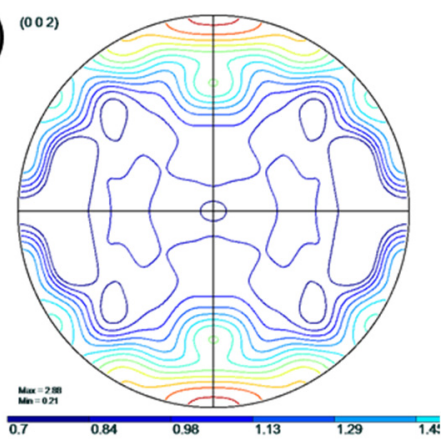

Figure 10. Macro texture of Mg-3Sn-2Al-1Zn-0.6Nd alloy under different hot deformation conditions: (a) $250{ }^{\circ} \mathrm{C} / 0.01 \mathrm{~s}^{-1}$, (b) $300{ }^{\circ} \mathrm{C} / 0.01 \mathrm{~s}^{-1}$, (c) $350{ }^{\circ} \mathrm{C} / 0.01 \mathrm{~s}^{-1}$, and (d) $350{ }^{\circ} \mathrm{C} / 0.001 \mathrm{~s}^{-1}$.

\section{Discussion}

CDRX is considered as one of the dynamic recrystallization mechanisms for $\mathrm{Mg}$ alloys, which induces the microstructure changes from the deformed state, recovered state into recrystallization. Generally, the CDRX nucleation mechanism is characterized by progressive lattice rotation for $\mathrm{Mg}$ alloys, and the cumulative misorientation reaches $10-15^{\circ}$, which means CDRX occurs in subgrain substructures [41,42]. Figure 11a,b shows the IPF maps and changes misorientations along a vector in the Mg-3Sn-2Al-1Zn- $0.6 \mathrm{Nd}$ alloy deformed at $300{ }^{\circ} \mathrm{C} / 0.01 \mathrm{~s}^{-1}$. The progressive lattice rotation had been developed from the grain interior to grain boundary along vector 1 (see Figure 11a). The origin point (cumulative) misorientation along vector 1 exceeded $15^{\circ}$, which suggested the occurrence of progressive lattice rotation. At the same time, fine DRX grains (like DRX grain A) were observed. These suggested that CDRX occurred in the Mg-3Sn-2Al-1Zn-0.6Nd alloy during hot deformation. A similar phenomenon was also reported in AZ31 Mg alloy during hot deformation [43]. To further study the orientations of DRX grains, the orientations and the lattice of the DRX grain A and its surrounding matrix grain were investigated (see Figure 11c-e). A similar orientations relationship and lattice were observed between the DRX grain A and its surrounding matrix grain. The matrix grain (coarse deformed grain) had the orientation distributed at the end of the $C D$ on the $\{0001\}$ pole figure, and the DRX grain A also had a similar orientation. This indicated that the coarse deformed grains and the CDRX grain had $<0001>/ / C D$ texture. The DRX grains by CDRX had similar orientations with the deformed matrix, which indicated the CDRX grains were formed by the progressive subgrains rotation adjacent to the initial grain boundaries. Zang et al. [15] also reported the orientations for the CDRX grains, and the CDRX grains have similar orientations with the deformed matrix. For the CDRX process, some mechanisms were developed to illustrate CDRX, i.e., CDRX by homogeneous misorientation increase, CDRX by progressive subgrains rotation near initial grain boundaries, and micro shear bandassisted CDRX. It can be concluded that CDRX by progressive subgrains rotation near initial grain boundaries was one of the DRX mechanisms in the Mg-3Sn-2Al-1Zn- $0.6 \mathrm{Nd}$ alloy during hot deformation. 

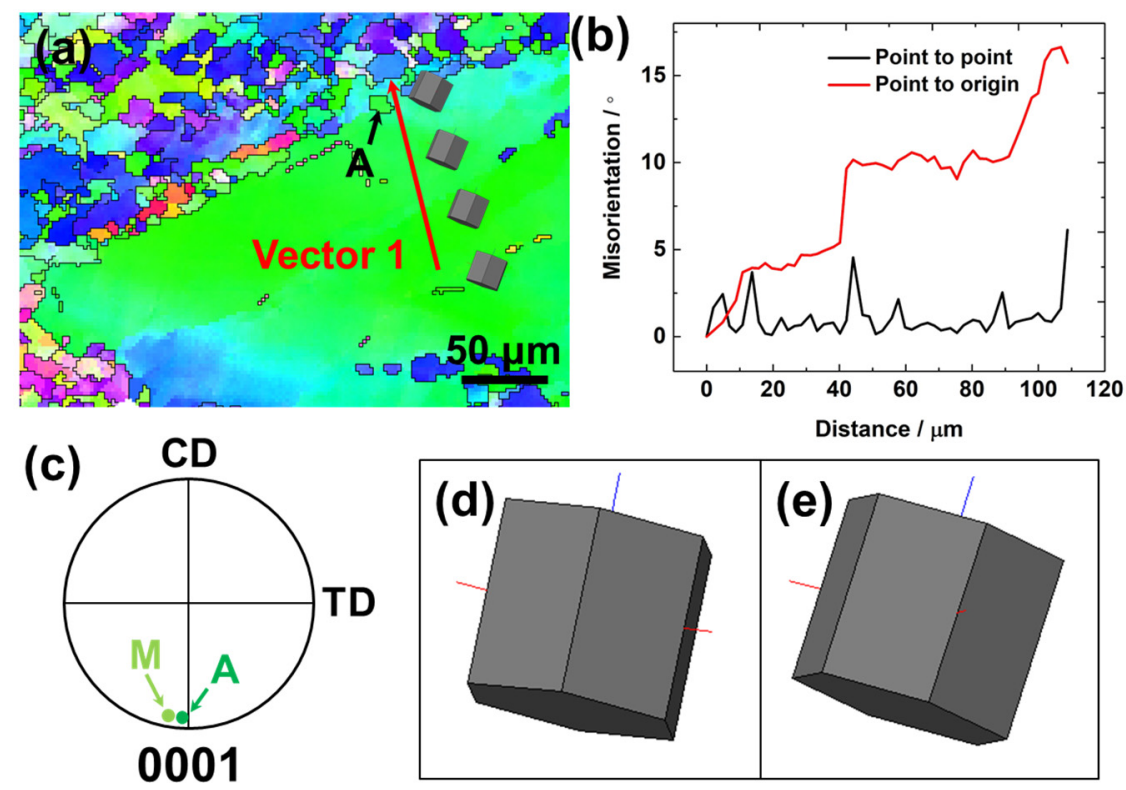

Figure 11. (a) EBSD IPF map of the alloy deformed at $300{ }^{\circ} \mathrm{C} / 0.01 \mathrm{~s}^{-1}$, (b) changes of misorientations along vector $1,(\mathbf{c})$ the orientations relationship on $\{0001\}$ pole figures of nuclei A with its surrounding matrix grain and schematic diagram showing the lattice of nuclei (d) A and (e) matrix grain.

From the EBSD IPF maps of the Mg-3Sn-2Al-1Zn-0.6Nd alloys (Figure 8), some fine DRX grains regions were also observed. In an attempt to investigate the DRX features in the fine DRX grains regions for the Mg-3Sn-2Al- $1 \mathrm{Zn}-0.6 \mathrm{Nd}$ alloy during hot deformation in detail, the magnified EBSD IPF map of the alloy deformed at $350{ }^{\circ} \mathrm{C} / 0.01 \mathrm{~s}^{-1}$ and the orientation of DRX grains are shown in Figure 12. The DRX grain A, DRX grain B, and DRX grain $C$ had random orientations on the $\{0001\}$ pole figure (see Figure $12 b$ ), and their lattices were also different. The DRX feature within fine DRX grains regions is different from the fine CDRX grains around the initial grain boundaries. Li et al. [44] also reported the orientations of DRX grains in the Mg-Li alloy during hot deformation. The orientations of adjacent DRX grains are quite different, which could lead to the weak texture in the $\mathrm{Mg}$-Li alloy. From Figure 12a, the grain boundary bulge was also observed in the deformed Mg-3Sn-2Al-1Zn-0.6Nd alloy, which is a typical DDRX feature. Thus, the mechanism of these DRX grains with random orientations is DDRX.

Besides the deformation of CDRX and DDRX, twinning is one of the most important deformation mechanisms of Mg alloys. The twinning was also observed in the OM and EBSD IPF maps of Mg-3Sn-2Al-1Zn-0.6Nd alloy during hot deformation (see Figures 7 and 8). The magnified EBSD IPF map of the alloy deformed at $300{ }^{\circ} \mathrm{C} / 0.01 \mathrm{~s}^{-1}$ is shown in Figure 13a. The misorientations along vector 1 through the twin grain $\mathrm{T}$ in Figure 13a are shown in Figure 13b, which indicates that the twin boundaries angle is $87.5^{\circ}$. The orientations and the lattice of the twin grain $\mathrm{T}$ and its surrounding matrix grain are Figure $13 \mathrm{c}-\mathrm{e}$. The orientations relationship between twin grain $\mathrm{T}$ and its surrounding matrix grain is [2110] $87.5^{\circ}$, which indicates that this twinning is $\{10 \overline{1} 2\}$ extension twin. The extension twin existed in the coarse deformed grains. The orientation of $\{10 \overline{1} 2\}$ extension twinning was quite different with its surrounding matrix grain, which shows crystal orientation rotation. It should be noted that the dominant texture for the Mg-3Sn-2Al-1Zn- $0.6 \mathrm{Nd}$ alloy after hot deformation is $<0001>/ / C D$ texture. The coarse deformed grains had the strong $<0001>/ / C D$ texture, the effects of $\{10 \overline{1} 2\}$ extension twinning and DDRX on crystal orientation were small [45]. 

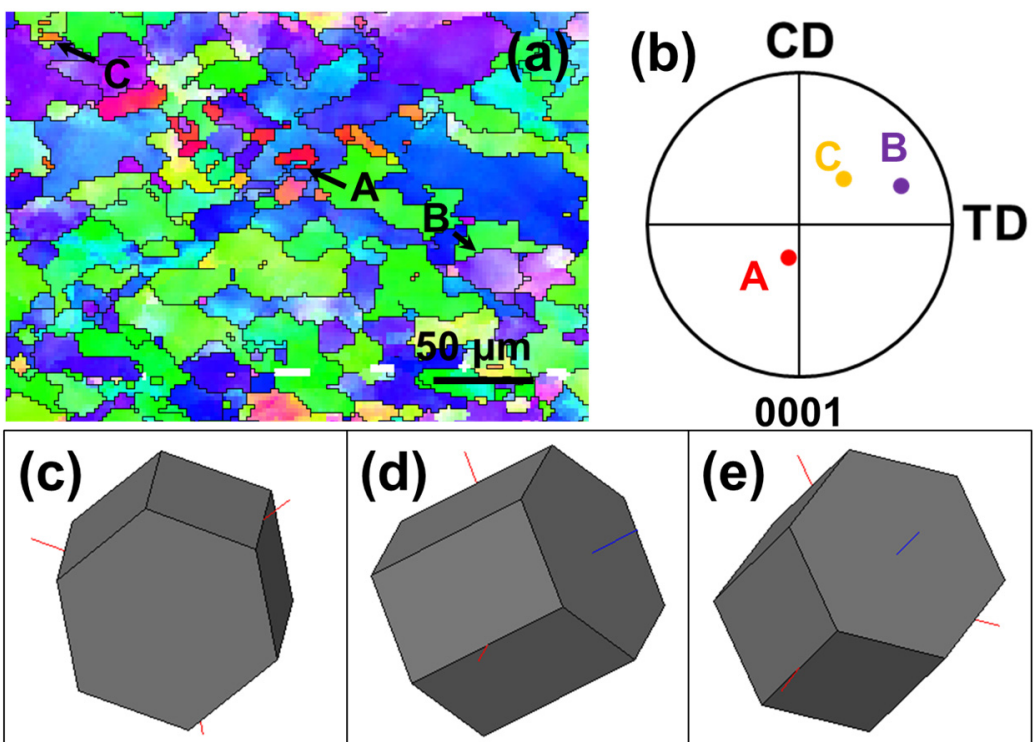

Figure 12. (a) EBSD IPF map of the alloy deformed at $350{ }^{\circ} \mathrm{C} / 0.01 \mathrm{~s}^{-1},(\mathbf{b})$ the orientations relationship on $\{0001\}$ pole figures of nuclei $A$, nuclei $B$ and nuclei $C$ and schematic diagram showing the lattice of nuclei (c) nuclei $\mathrm{A}$, (d) nuclei $\mathrm{B}$, and (e) nuclei $\mathrm{C}$.
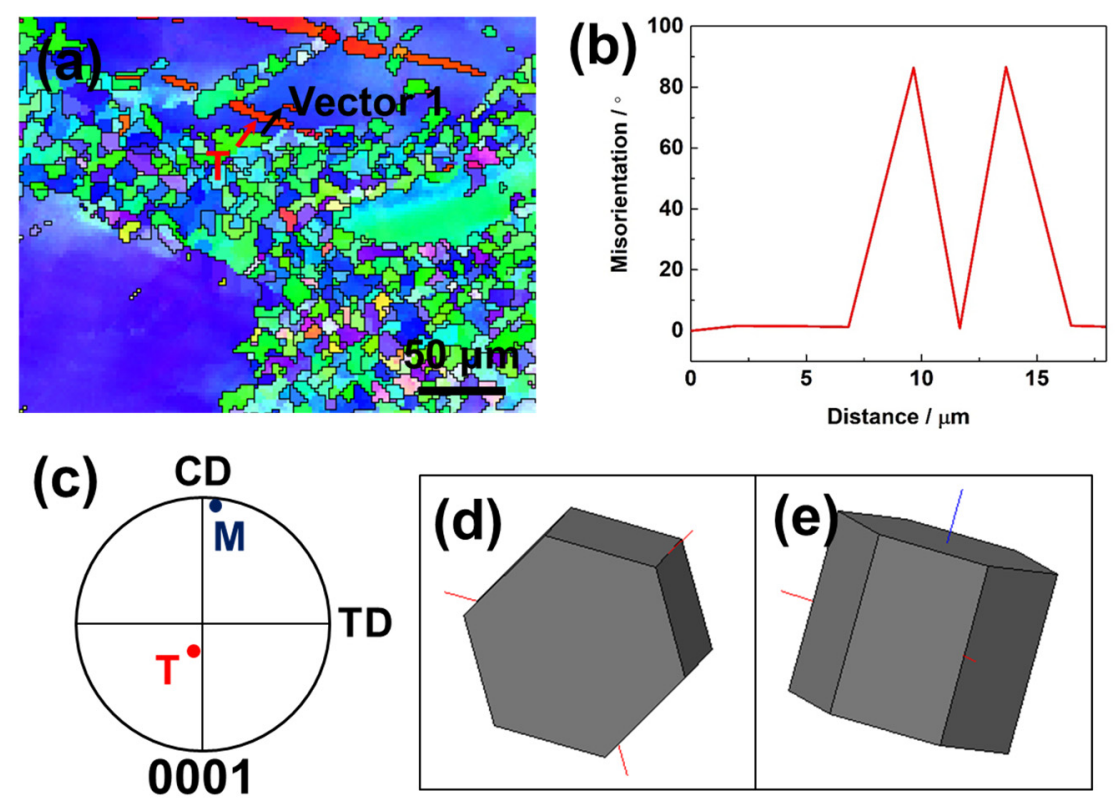

Figure 13. (a) EBSD IPF map of the alloy deformed at $300{ }^{\circ} \mathrm{C} / 0.01 \mathrm{~s}^{-1}$, (b) changes of misorientations along with Vector 1 , (c) the orientations relationship on $\{0001\}$ pole figures of twin grain $\mathrm{T}$ with its surrounding matrix grain and schematic diagram showing the lattice of (d) twin grain $\mathrm{T}$ and (e) matrix grain.

\section{Conclusions}

(1) Constitutive equations relating the flow stress, the strain rate, and the deformation temperature of $\mathrm{Mg}-3 \mathrm{Sn}-2 \mathrm{Al}-1 \mathrm{Zn}-0.6 \mathrm{Nd}$ alloy during hot deformation are established and given as:

$$
\dot{\varepsilon}=8.72165 \times 10^{11}[\sinh (0.01075 \sigma)]^{5.83763} \exp \left(-\frac{148102.52}{R T}\right)
$$

(2) The processing map at the strain of 0.8 based on the dynamic materials model (DMM) was obtained. The processing map exhibited a stable domain (temperature range of 
$320-350{ }^{\circ} \mathrm{C}$ and strain rate range of $0.001-0.04 \mathrm{~s}^{-1}$ ) with high power dissipation efficiency $(>30 \%)$

(3) A large number of fine dynamic recrystallization grains and deformed twinning existed in the alloy after hot deformation. The size of DRX grains increased with the increase of deformation temperature or the decrease of strain rate. The dominant texture of the $\mathrm{Mg}$ $3 \mathrm{Sn}-2 \mathrm{Al}-1 \mathrm{Zn}-0.6 \mathrm{Nd}$ alloy is $<0001>/ / \mathrm{CD}$ texture by EBSD analysis after hot deformation.

(4) The continuous DRX (CDRX) and discontinuous DRX (DDRX) were the dominant recrystallization mechanism, and $\{10 \overline{1} 2\}$ extension twinning also occurred in the alloy during hot deformation. Discontinuous dynamic recrystallization (DDRX) grains have random orientations, and continuous dynamic recrystallization (CDRX) by progressive subgrains rotation near initial grain boundaries also occurred, which have similar orientations with the matrix, can be verified by XRD macrotexture.

Author Contributions: Conceptualization, Y.G. and Q.Z.; methodology, Y.G.; software, Y.D.; validation, P.C., Y.G. and Z.Z.; formal analysis, Y.G. and Q.Z.; investigation, Y.G. and Q.Z.; resources, Y.G.; data curation, Y.D. and P.C.; writing-original draft preparation, Y.G.; writing-review and editing, Y.G.; visualization, Y.D.; supervision, Q.Z.; project administration, Y.G.; funding acquisition, Y.G. All authors have read and agreed to the published version of the manuscript.

Funding: Doctoral Research Start-up Fund of Jiangsu University of Science and Technology (No.1062932101), The authors are grateful for financial support from Guangdong Basic and Applied Basic Research Foundation (No. 2020A1515110394).

Institutional Review Board Statement: Not required.

Informed Consent Statement: Informed consent was obtained from all subjects involved in the study.

Data Availability Statement: The data that support the findings of this study are available on request from the corresponding author.

Conflicts of Interest: The authors declare no conflict of interest.

\section{References}

1. Kim, J.-Y.; Byeon, J.-W. Quantitative relation of discontinuous and continuous Mg17Al12 precipitates with corrosion rate of AZ91D magnesium alloy. Mater. Charact. 2021, 174, 111015. [CrossRef]

2. Prakash, P.; Wells, M.A.; Williams, B.W. Hot deformation of cast AZ31 and AZ80 magnesium alloys-Influence of Al content on microstructure and texture development. J. Alloys Compd. 2022, 897, 162876. [CrossRef]

3. Jiang, W.; Wang, J.; Zhao, W.; Liu, Q.; Jiang, D.; Guo, S. Effect of Sn addition on the mechanical properties and bio-corrosion behavior of cytocompatible Mg-4Zn based alloys. J. Magnes. Alloy. 2019, 7, 15-26. [CrossRef]

4. Guo, J.; Chang, L.; Zhao, Y.; Jin, Y. Effect of Sn and Y addition on the microstructural evolution and mechanical properties of hot-extruded Mg-9Li-3Al alloy. Mater. Charact. 2019, 148, 35-42. [CrossRef]

5. Zhou, T.; Zhang, Q.; Li, Q.; Wang, L.; Li, Q.; Liu, D. A simultaneous enhancement of both strength and ductility by a novel differential-thermal ECAP process in Mg-Sn-Zn-Zr alloy. J. Alloys Compd. 2021, 889, 161653. [CrossRef]

6. Jiang, L.; Huang, W.; Zhang, D.; Guo, F.; Xue, H.; Xu, J.; Pan, F. Effect of Sn on the microstructure evolution of AZ80 magnesium alloy during hot compression. J. Alloys Compd. 2017, 727, 205-214. [CrossRef]

7. Zou, J.; Chen, J.; Yan, H.; Xia, W.; Su, B.; Lei, Y.; Wu, Q. Effects of Sn addition on dynamic recrystallization of Mg-5Zn-1Mn alloy during high strain rate deformation. Mater. Sci. Eng. A 2018, 735, 49-60. [CrossRef]

8. Wu, G.; Wang, C.; Sun, M.; Ding, W. Recent developments and applications on high-performance cast magnesium rare-earth alloys. J. Magnes. Alloy. 2021, 9, 1-20. [CrossRef]

9. Xu, X.; Chen, X.; Du, W.; Geng, Y.; Pan, F. Effect of Nd on microstructure and mechanical properties of as-extruded Mg-Y-Zr-Nd alloy. J. Mater. Sci. Technol. 2017, 33, 926-934. [CrossRef]

10. Xin, R.; Li, L.; Zeng, K.; Song, B.; Liu, Q. Structural examination of aging precipitation in a Mg-Y-Nd alloy at different temperatures. Mater. Charact. 2011, 62, 535-539. [CrossRef]

11. Jinwang, Z.; Shebin, W.; Junyuan, Z.; Jinling, Z.; Bingshe, X. Effects of Nd on microstructures and mechanical properties of AM60 magnesium alloy in vacuum melting. Rare Met. Mater. Eng. 2009, 38, 1141-1145. [CrossRef]

12. Lv, S.; Meng, F.; Lu, X.; Yang, Q.; Qiu, X.; Duan, Q.; Meng, J. Influence of Nd addition on microstructures and mechanical properties of a hot-extruded Mg-6.0 Zn-0.5 Zr (wt.\%) alloy. J. Alloys Compd. 2019, 806, 1166-1179. [CrossRef]

13. WANG, Y.-X.; FU, J-W.; YANG, Y.-S. Effect of Nd addition on microstructures and mechanical properties of AZ80 magnesium alloys. Trans. Nonferrous Met. Soc. China 2012, 22, 1322-1328. [CrossRef] 
14. Momeni, A.; Dehghani, K. Hot working behavior of 2205 austenite-ferrite duplex stainless steel characterized by constitutive equations and processing maps. Mater. Sci. Eng. A 2011, 528, 1448-1454. [CrossRef]

15. Zang, Q.; Yu, H.; Lee, Y.-S.; Kim, M.-S.; Kim, H.-W. Hot deformation behavior and microstructure evolution of annealed Al-7.9 Zn-2.7 Mg-2.0 Cu (wt\%) alloy. J. Alloys Compd. 2018, 763, 25-33. [CrossRef]

16. Li, N.; Zhao, C.; Jiang, Z.; Zhang, H. Flow behavior and processing maps of high-strength low-alloy steel during hot compression. Mater. Charact. 2019, 153, 224-233. [CrossRef]

17. Mosleh, A.; Mikhaylovskaya, A.; Kotov, A.; Sitkina, M.; Mestre-Rinn, P.; Kwame, J. Superplastic deformation behavior of ultrafine-grained Ti-1V-4Al-3Mo alloy: Constitutive modeling and processing map. Mater. Res. Express 2019, 6, 096584. [CrossRef]

18. Yakovtseva, O.; Sitkina, M.; Mosleh, A.O.; Mikhaylovskaya, A. High strain rate superplasticity in Al-Zn-Mg-based alloy: Microstructural design, deformation behavior, and modeling. Materials 2020, 13, 2098. [CrossRef]

19. Zang, Q.; Chen, H.; Lee, Y.-S.; Yu, H.; Kim, M.-S.; Kim, H.-W. Improvement of anisotropic tensile properties of Al-7.9Zn-2.7Mg2.0 Cu alloy sheets by particle stimulated nucleation. J. Alloys Compd. 2020, 828, 154330. [CrossRef]

20. Evans, R.; Scharning, P. Axisymmetric compression test and hot working properties of alloys. Mater. Sci. Technol. 2001, 17, 995-1004. [CrossRef]

21. Churyumov, A.Y.; Khomutov, M.; Tsar'Kov, A.; Pozdnyakov, A.; Solonin, A.; Efimov, V.; Mukhanov, E. Study of the structure and mechanical properties of corrosion-resistant steel with a high concentration of boron at elevated temperatures. Phys. Met. Metallogr. 2014, 115, 809-813. [CrossRef]

22. Wan, Z.; Hu, L.; Sun, Y.; Wang, T.; Li, Z. Hot deformation behavior and processing workability of a Ni-based alloy. J. Alloys Compd. 2018, 769, 367-375. [CrossRef]

23. Wang, C.; Wang, X.; Chang, H.; Wu, K.; Zheng, M. Processing maps for hot working of ZK60 magnesium alloy. Mater. Sci. Eng. A 2007, 464, 52-58. [CrossRef]

24. Cheng, W.; Bai, Y.; Ma, S.; Wang, L.; Wang, H.; Yu, H. Hot deformation behavior and workability characteristic of a fine-grained Mg-8Sn-2Zn-2Al alloy with processing map. J. Mater. Sci. Technol. 2019, 35, 1198-1209. [CrossRef]

25. Guo, Y.; Xuanyuan, Y.; Ly, X.; Yang, S. Hot deformation behaviors of the Mg-3Sn-2Al-1Zn alloy: Investigation on its constitutive equation, processing map, and microstructure. Materials 2020, 13, 312. [CrossRef]

26. Guo, Y.; Xuanyuan, Y.; Lia, C.; Yang, S. Characterization of hot deformation behavior and processing maps of Mg-3Sn-2Al-1Zn-5Li magnesium alloy. Metals 2019, 9, 1262. [CrossRef]

27. Hadadzadeh, A.; Mokdad, F.; Wells, M.; Chen, D. Modeling dynamic recrystallization during hot deformation of a casthomogenized Mg-Zn-Zr alloy. Mater. Sci. Eng. A 2018, 720, 180-188. [CrossRef]

28. Zang, Q.; Yu, H.; Lee, Y.-S.; Kim, M.-S.; Kim, H.-W. Effects of initial microstructure on hot deformation behavior of Al-7.9Zn2.7Mg-2.0Cu (wt\%) alloy. Mater. Charact. 2019, 151, 404-413. [CrossRef]

29. Tsao, L.; Chen, C.; Wu, R.; Chang, S.; Chen, R. Plastic flow behavior, microstructure, and corrosion behavior of AZ61 Mg alloy during hot compression deformation. J. Manuf. Process. 2015, 18, 167-174. [CrossRef]

30. Lingyun, W.; Guangjie, H.; Yonge, F.; Zhiwen, L.; Fusheng, P. Hot deformation kinetics of magnesium alloy AZ31. J. Wuhan Univ. Technol. Mater. Sci. Ed. 2006, 21, 15-17. [CrossRef]

31. Cheng, W.-l.; Que, Z.-p.; Zhang, J.-s.; Xu, C.-x.; Liang, W.; You, B.S.; Park, S.S. Compressive deformation behavior of an indirect-extruded Mg-8Sn-1Al-1Zn alloy. Int. J. Miner. Metall. Mater. 2013, 20, 49-56. [CrossRef]

32. McQueen, H.J.; Ryan, N. Constitutive analysis in hot working. Mater. Sci. Eng. A 2002, 322, 43-63. [CrossRef]

33. Zener, C.; Hollomon, J.H. Effect of strain rate upon plastic flow of steel. J. Appl. Phys. 1944, 15, 22-32. [CrossRef]

34. Prasad, Y.; Gegel, H.; Doraivelu, S.; Malas, J.; Morgan, J.; Lark, K.; Barker, D. Modeling of dynamic material behavior in hot deformation: Forging of Ti-6242. Metall. Trans. A 1984, 15, 1883-1892. [CrossRef]

35. Prasad, Y.; Seshacharyulu, T. Processing maps for hot working of titanium alloys. Mater. Sci. Eng. A 1998, 243, 82-88. [CrossRef]

36. Li, B.; Pan, Q.; Zhang, Z.; Li, C. Characterization of flow behavior and microstructural evolution of Al-Zn-Mg-Sc-Zr alloy using processing maps. Mater. Sci. Eng. A 2012, 556, 844-848. [CrossRef]

37. Yan, J.; Pan, Q.; Li, B.; Huang, Z.; Liu, Z.; Yin, Z. Research on the hot deformation behavior of Al-6.2Zn- $0.70 \mathrm{Mg}-0.3 \mathrm{Mn}-0.17 \mathrm{Zr}$ alloy using processing map. J. Alloys Compd. 2015, 632, 549-557. [CrossRef]

38. Sun, Y.; Cao, Z.; Wan, Z.; Hu, L.; Ye, W.; Li, N.; Fan, C. 3D processing map and hot deformation behavior of 6A02 aluminum alloy. J. Alloys Compd. 2018, 742, 356-368. [CrossRef]

39. Chen, X.; Liao, Q.; Niu, Y.; Jia, Y.; Le, Q.; Ning, S.; Hu, C.; Hu, K.; Yu, F. Comparison study of hot deformation behavior and processing map of AZ80 magnesium alloy casted with and without ultrasonic vibration. J. Alloys Compd. 2019, 803, 585-596. [CrossRef]

40. Cai, Y.; Wan, L.; Guo, Z.; Sun, C.; Yang, D.; Zhang, Q.; Li, Y. Hot deformation characteristics of AZ80 magnesium alloy: Work hardening effect and processing parameter sensitivities. Mater. Sci. Eng. A 2017, 687, 113-122. [CrossRef]

41. Lin, Y.; Wu, X.-Y.; Chen, X.-M.; Chen, J.; Wen, D.-X.; Zhang, J.-L.; Li, L.-T. EBSD study of a hot deformed nickel-based superalloy. J. Alloys Compd. 2015, 640, 101-113. [CrossRef]

42. Mandal, S.; Bhaduri, A.; Sarma, V.S. A study on microstructural evolution and dynamic recrystallization during isothermal deformation of a Ti-modified austenitic stainless steel. Metall. Mater. Trans. A 2011, 42, 1062-1072. [CrossRef]

43. Beer, A.G.; Barnett, M. Microstructural development during hot working of Mg-3Al-1Zn. Metall. Mater. Trans. A 2007, 38, 1856-1867. [CrossRef] 
44. Li, X.; Ren, L.; Le, Q.; Jin, P.; Cheng, C.; Wang, T.; Wang, P.; Zhou, X.; Chen, X.; Li, D. The hot deformation behavior, microstructure evolution and texture types of as-cast Mg-Li alloy. J. Alloys Compd. 2020, 831, 154868. [CrossRef]

45. Zhang, M.; Wang, J.; Zhu, Y.; Zhang, L.; Jin, P. Ex-situ EBSD analysis of hot deformation behavior and microstructural evolution of Mg-1Al-6Y alloy via uniaxial compression. Mater. Sci. Eng. A 2020, 775, 138978. [CrossRef] 